\title{
Scarless and sequential gene modification in Pseudomonas using PCR product flanked by short homology regions
}

Rubing Liang, Jianhua Liu*

\begin{abstract}
Background: The lambda Red recombination system has been used to inactivate chromosomal genes in various bacteria and fungi. The procedure consists of electroporating a polymerase chain reaction (PCR) fragment containing antibiotic cassette flanked by homology regions to the target locus into a strain that can express the lambda Red proteins (Gam, Bet, Exo).

Results: Here a scarless gene modification strategy based on the Red recombination system has been developed to modify Pseudomonas genome DNA via sequential deletion of multiple targets. This process was mediated by plasmid pRKaraRed encoding the Red proteins regulated by $P_{B A D}$ promoter, which was functional in $P$. aeruginosa as well as in other bacteria. First the target gene was substituted for the sacB-bla cassette flanked by short homology regions (50 bp), and then this marker gene cassette could be replaced by the PCR fragment flanking itself, generating target-deleted genome without any remnants and no change happened to the surrounding region. Twenty genes involved in the synthesis and regulation pathways of the phenazine derivate, pyocyanin, were modified, including one single-point mutation and deletion of two large operons. The recombination efficiencies ranged from $88 \%$ to $98 \%$. Multiple-gene modification was also achieved, generating a triple-gene deletion strain PCA (PAO1, $4 p h z H \Delta p h z M \triangle p h z S)$, which could produce another phenazine derivate, phenazine-1carboxylic acid (PCA), efficiently and exclusively.

Conclusions: This lambda Red-based technique can be used to generate scarless and sequential gene modification mutants of $P$. aeruginosa efficiently, using one-step PCR product flanked by short homology regions. Single-point mutation, scarless deletion of genes can be achieved easily in less than three days. This method may give a new way to construct genetically modified $P$. aeruginosa strains more efficiently and advance the regulatory network study of this organism.
\end{abstract}

\section{Background}

Obtainment of the genome sequences of more and more bacteria have provided researchers a wealth of information to restructure custom-designed microbes for therapeutic and industrial applications [1-3]. One of the most common approaches is sequence-specific deletion or insertion of the target genes or DNA fragments, and various methods have been developed based on the RecA-independent homologous recombination, such as RecET and lambda Red recombination system [4-8]. In these recombination events, selection markers, usually antibiotic markers are

* Correspondence: jianhualiudl@sjtu.edu.cn

School of Life Science \& Technology, Shanghai Jiao Tong University, 800 Dong-Chuan Road, Shanghai 200240, China needed to confirm the modification procedure, which may have influence on further manipulation. To solve this problem, the Flp/FRT and Cre/loxP site-specific recombination systems have been used for the precise excision of selection markers. However, even combined with these systems, one copy of FRT or loxP site still remains on the genome after excision $[9,10]$.

P. aeruginosa is a gram-negative opportunistic human pathogen of growing clinical importance. The sequence analysis on the $6.3 \mathrm{Mb}$ genome of $P$. aeruginosa PAO1 revealed 5700 predicted open reading frames (ORF) [11]. Many genetic tools have been developed for its genomescale and proteome-scale research, such as commercial (Affymetrix, Santa Clara, CA) P. aeruginosa GeneChips ${ }^{\circ}$ 
for transcriptome analysis and the transposon mutants library for sequence-defined mutants [12-15]. Almost in all of these methods, it is necessary to use the suicide vector and the conjugation transfer to isolate the defined mutant, which is a quite tedious process. In addition, to make unmarked deletion mutants, researchers have developed several methods combining the counterselectable markers $(s a c B)$ with the site-specific Flp or Cre recombinase $[16,17]$. However, these methods can not generate the true "scarless" mutants.

Here a two-step approach was described to perform the scarless and sequential genome modification using onestep PCR product with short (50 bp) homology regions. The homologous recombination process was mediated by an RK2-derived plasmid, pRKaraRed, expressing the genes of lambda-Red system (gam, bet and exo) from the arabinose-inducible $P_{B A D}$ promoter. Single gene modification could be finished in three days and the efficiency is higher than $88 \%$. Twelve scarless deletion mutants of different genes, two deletion mutants of large operons, and one single-point mutation were successfully constructed. Furthermore a strain PCA (PAO1, $\Delta p h z H \Delta p h z M \Delta p h z S)$ with deletions in three genes was also generated, which could produce the phenazine-1-acid exclusively and efficiently. This strategy may simplify the genetic manipulation to $P$. aeruginosa and fasten relevant research.

\section{Results}

\section{Lambda Red-mediated scarless gene modification in $P$. aeruginosa}

The map of plasmid pRKaraRed was shown in Fig. 1. The backbone was originated from pDN18, in which the oriV and $\operatorname{trf} A$ regions were used to support the plasmid replication and stable maintenance in $P$. aeruginosa, oriT region was considered functional for the conjugal transfer among any gram-negative bacterial host virtually and tet $A$ was a tetracycline resistance gene [18-20]. The $P_{B A D}$ promoter was used to regulate the expression of lambda Red proteins (Gam, Bet, Exo). The nucleotide sequence of plasmid pRKaraRed was deposited in GenBank under the accession number GU186864.

Initially, $p h z S$ was selected as target because the phenotype of the mutant could be differentiated from that of the wild type by its inability to produce the pseudomonas blue phenazine pigment, pyocyanin, lack of which resulting a yellowish culture.

Scarless gene modification could be achieved in two steps (Fig. 2). First the sacB-bla cassette flanked by short homology regions $\mathrm{A}$ and $\mathrm{B}$ adjacent to the target was amplified and electro-transformed into the PAO1/pRKaraRed competent cells. Positive colonies $\left(\mathrm{Carb}^{\mathrm{R}} \mathrm{Tet}^{\mathrm{R}}\right)$ were then electro-transformed to delete the markers with the sacB-bla removal cassette, which contained the upstream homology region $\mathrm{A}$ and the downstream homology

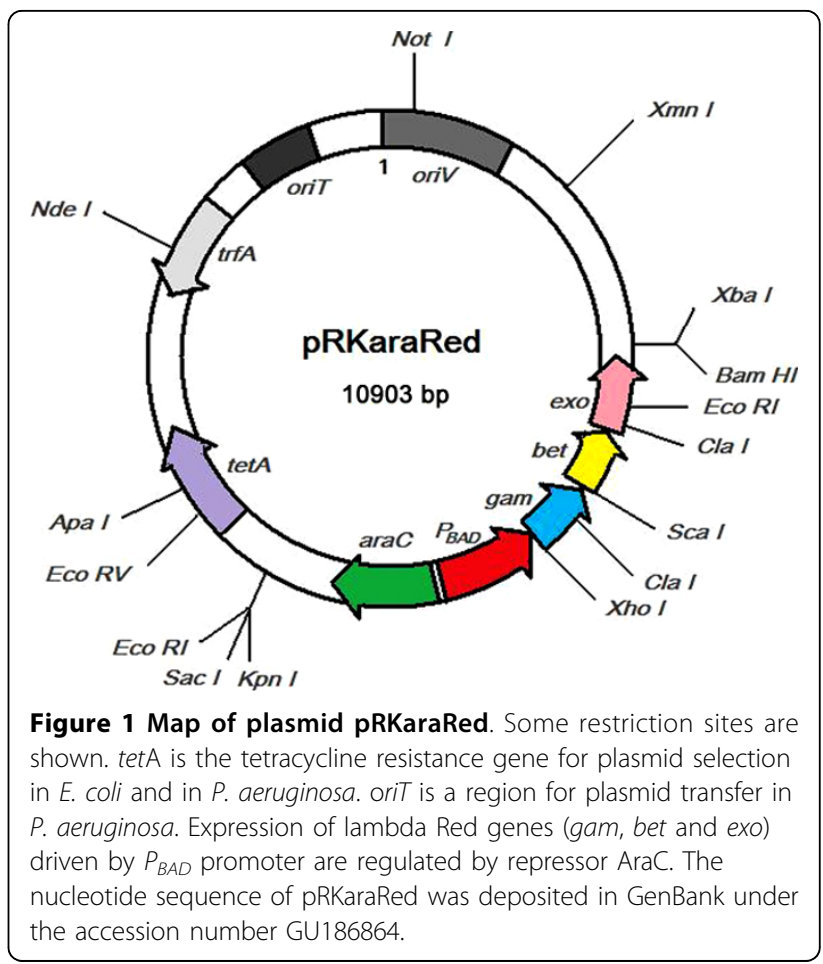

region from B to $C(\sim 1000 \mathrm{bp})$. And the $\mathrm{Suc}^{\mathrm{R}} \mathrm{Carb}^{\mathrm{S}}$ colonies were regarded as positive recombinants.

The $P_{B A D}$ promoter on plasmid pRKaraRed could be induced by L-arabinose and then the lambda Red proteins could be expressed efficiently, endowing the PAO1/ pRKaraRed cells with recombination capability. We first assessed whether 50 bp homology was sufficient to enable efficient homologous recombination between the target

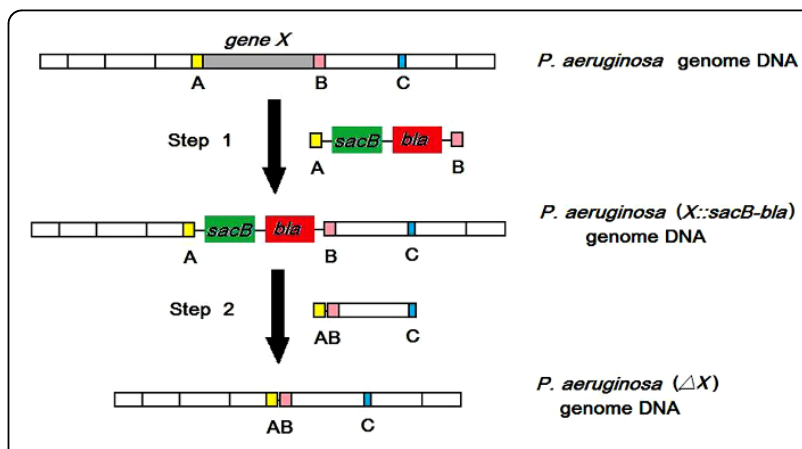

Figure 2 Schematic description of the scarless gene modification approach. The first-step of homologous recombination would substitute the genomic target gene $X$ for the PCR-amplified sacB-bla cassette flanked by the A and B homology regions. The transformants were screened on LB plates containing Carb $(500 \mu \mathrm{g} / \mathrm{ml})$ and Tet $(50 \mu \mathrm{g} / \mathrm{ml})$. The second-step of recombination would replace the sacB-bla cassette with PCRamplified fragments flanked by the $A B$ and $C$ homology regions. As a result, strain with deleted gene $X$ and without any remnant on chromosome DNA would be obtained. The transformants of this step were selected on LB plates containing $10 \%$ sucrose. 
and the PCR cassette, which is generally sufficient in E. coli [7]. Results showed that the recombination reactions with $1 \times 10^{9}$ cells and aliquots of 1 or $2 \mu$ g electroporated PCR products could generate 30 80 $\mathrm{Carb}^{\mathrm{R}}$ transformants, and the colonies number would double approximately when $4 \mu \mathrm{g}$ DNA was used. Controls (uninduced cells, induced cells without plasmid, and induced cells without DNA fragments) have no transformants. Then the insertion of the sacB-bla cassette and the pyocyanin producing ability of all the $\mathrm{Carb}^{\mathrm{R}}$ colonies were analyzed. And almost all the colonies were positive recombinants (Table 1). The recombination reactions using PCR cassettes flanked by other length of homology regions (60 bp and $100 \mathrm{bp}$ ) were also performed, and the recombination efficiency was slightly increased (Table 1 ). Therefore, $50 \mathrm{bp}$ homology was enough to promote the efficient homologous recombination.

The influences of the L-arabinose concentration and the induction time on the recombination efficiency were also analyzed. Results indicated that when the concentration of L-arabinose went up, the recombination efficiency also increased gradually which could reach the maximum at the concentration of $0.2 \%$ and keep stable. Induction time also had influence on the recombination efficiency and efficient recombination could be achieved after the cells were induced with $0.2 \% \mathrm{~L}$-arabinose for at least three hours (Table 1).

\section{Gene modifications in P. aeruginosa PAO1}

Using this pRKaraRed mediated strategy, several mutants were constructed, including twelve deletion mutants of different genes, two deletion mutants of large operons, and one single-point mutation. And the length of modified regions ranged from $1 \mathrm{bp}$ to $6.3 \mathrm{~kb}$ (Table 2, Fig. 3). These twelve genes were involved in the synthesis and regulation of pyocyanin and the two operons were the pyocyanin synthesis operons. The point mutation was made at the site 761 of the $p h z S$ gene, changing the nucleotide $\mathrm{A}$ to $\mathrm{T}$, which could produce a Bam HI restriction site. Typically 2 $\mu \mathrm{g}$ DNA was electroporated into the PAO1/pRKaraRed competent cells and about 26 78 colonies $\left(\mathrm{Carb}^{\mathrm{R}} \mathrm{Tet}^{\mathrm{R}}\right)$ could be obtained. The recombinant efficiencies were about 94 99\%, no significant correlation to the size of target gene (Table 2). After the second-step recombination and the sucrose counter-selection, nearly all of the survival colonies were positive recombinants. Indeed, as summarized in Table 2, the overall efficiency of the scarless deletion process ranged from $88 \%$ to $98 \%$.

\section{Sequential gene deletion and construction of strain PCA}

Two-step homogeneous recombination was required for the modification of each gene and the modifications of multiple genes could be easily achieved after several rounds. On this basis, sequential deletion of two, three and four genes were performed successfully. The

Table 1 Efficiencies of pRKaraRed-mediated recombination under different conditions

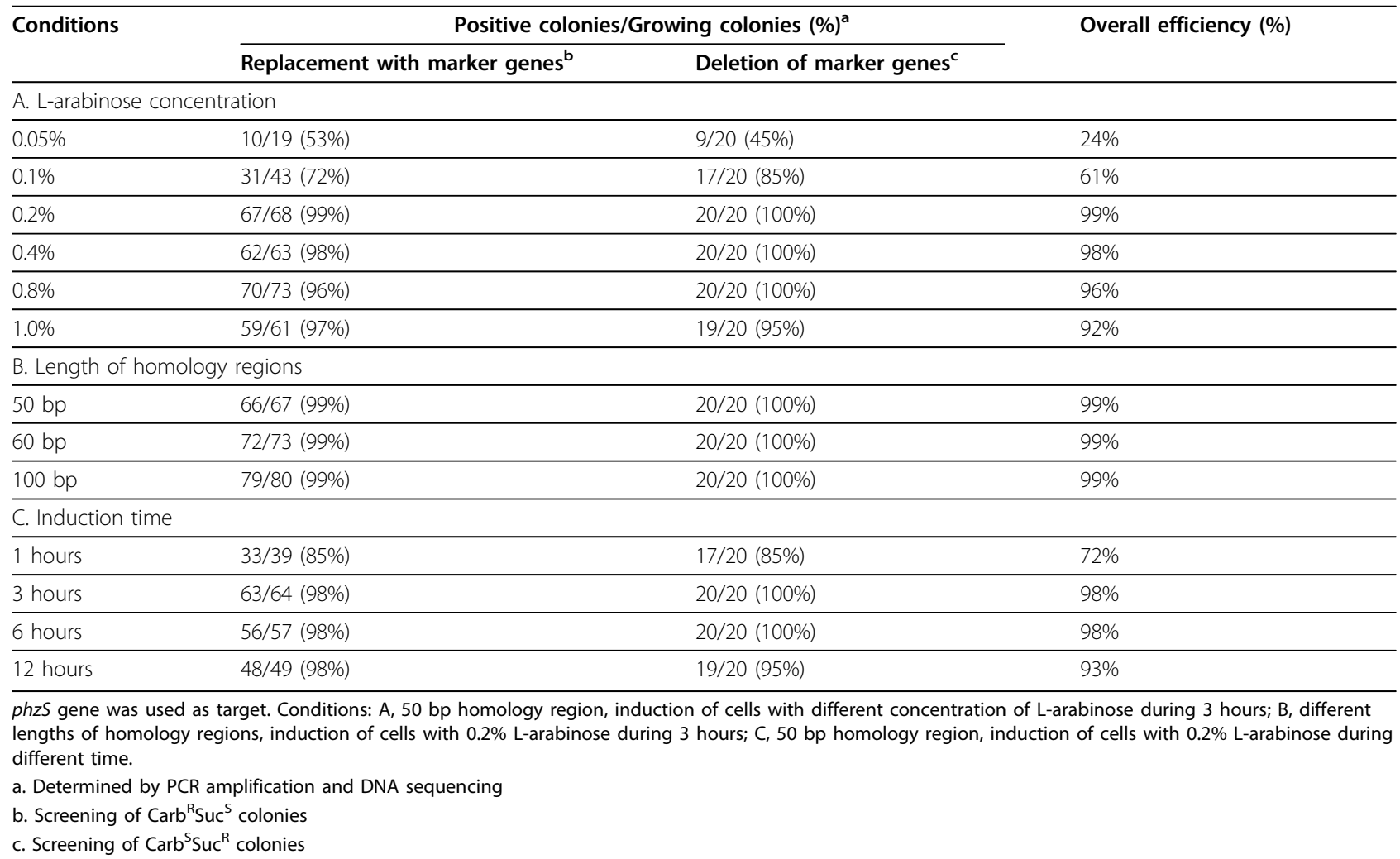


Table 2 Efficiencies of pRKaraRed-mediated scarless modification to different targets

\begin{tabular}{|c|c|c|c|c|}
\hline \multirow[t]{2}{*}{ Target } & \multirow[t]{2}{*}{ Size (bp) } & \multicolumn{2}{|c|}{ Positive colonies/Growing colonies (\%) ${ }^{a}$} & \multirow[t]{2}{*}{ Overall efficiency (\%) } \\
\hline & & Replacement using sacB-bla cassette ${ }^{\mathrm{b}}$ & Deletion of $s a c B-b l a$ cassette $^{c}$ & \\
\hline \multicolumn{5}{|c|}{ A. Deletion of genes } \\
\hline $\mathrm{rsm} A$ & 186 & 43/44 (98\%) & 19/20 (95\%) & $93 \%$ \\
\hline las 1 & 606 & $53 / 54(98 \%)$ & $20 / 20(100 \%)$ & $98 \%$ \\
\hline gac A & 645 & $49 / 50(98 \%)$ & 18/20 (90\%) & $88 \%$ \\
\hline $\operatorname{asc} R$ & 714 & $36 / 37(97 \%)$ & 19/20 (95\%) & $92 \%$ \\
\hline las $R$ & 720 & $56 / 57(98 \%)$ & $20 / 20(100 \%)$ & $98 \%$ \\
\hline$r h / R$ & 762 & $59 / 61(97 \%)$ & $20 / 20(100 \%)$ & $97 \%$ \\
\hline phz M & 1005 & $65 / 68(96 \%)$ & 19/20 (95\%) & $91 \%$ \\
\hline rpo $s$ & 1005 & $46 / 47(98 \%)$ & $20 / 20(100 \%)$ & $98 \%$ \\
\hline phz S & 1209 & 70/72 (97\%) & $20 / 20(100 \%)$ & $97 \%$ \\
\hline phz H & 1833 & 68/69 (99\%) & 19/20 (95\%) & $89 \%$ \\
\hline rpo D & 1854 & $52 / 54(96 \%)$ & $20 / 20(100 \%)$ & $96 \%$ \\
\hline pts $P$ & 2280 & 78/80 (98\%) & 19/20 (95\%) & $93 \%$ \\
\hline \multicolumn{5}{|c|}{ B. Single-point mutation } \\
\hline phz S & 1 & $24 / 26(94 \%)$ & 19/20 (95\%) & $89 \%$ \\
\hline \multicolumn{5}{|l|}{ (A761T) } \\
\hline \multicolumn{5}{|c|}{ C. Deletion of operons } \\
\hline phz A1-G1 & 6267 & 47/50 (94\%) & 19/20 (95\%) & $89 \%$ \\
\hline phz A2-G2 & 6273 & $61 / 63(97 \%)$ & $20 / 20(100 \%)$ & $97 \%$ \\
\hline
\end{tabular}

a. Determined by PCR amplification and DNA sequencing

b. Screening of $\mathrm{Carb}^{\mathrm{R}} \mathrm{Suc}^{\mathrm{S}}$ colonies

c. Screening of Carb $^{\mathrm{S}} \mathrm{Suc}^{\mathrm{R}}$ colonies

construction of strain PCA with deletions in three genes, $p h z H$, $p h z M$ and $p h z S$, was shown as an example. Proteins PhzS, PhzH and PhzM are involved in the conversion of phenazine-1-carboxylic acid (PCA) into 1-hydroxyphenazine (1-OH-PHZ), phenazine-1-carboxyamide (PCN) and pyocyanin (PYO) [17]. After three rounds of the two-step recombination, these three genes were deleted sequentially and scarlessly (Fig. 4A). As revealed by the HPLC analysis, at least four phenazine derivatives could be detected from the cultured media of PAO1 strain, corresponding to the PCA, 1-OH-PHZ, PCN and PYO, respectively. In the HPLC plot of PCA strain, only one peak representing PCA was detected, and the yield of PCA was higher than that of PAO1 strain (Fig. 4B), indicating that strain PCA could produce PCA efficiently and exclusively.

\section{Discussion}

Lambda Red recombination system first described in E. coli has been successfully applied to Yersinia, Salmonella, Shigella and Serratia [6,7,21-25]. The procedures involve the homologous recombination between the region of interest and a PCR product containing antibiotic cassette flanked by homology region. Although this efficient method may be applicable to other bacteria, adaptations are frequently required, such as the homology length and recombination steps [22].

In $P$. aeruginosa, construction of markerless deletion mutants is still a time-consuming and labor-intensive process. Two different plasmids were used in the traditional procedure. The first plasmid was transformed for targeting a selected region and the second plasmid was re-transformed for the unmarked deletion of the antibiotic cassette by Flp recombinase [16]. This recombination procedure including multiple steps needs several days to accomplish one gene modification and the recombination efficiency is not very high. Furthermore, the produced "unmarked" deletion is not scarless, as normally one FRT site was left. In 2008, lambda Red system and three-step PCR products were used to replace the target gene with antibiotic cassette in $P$. aeruginosa PA14, which confirmed the possibility of using the lambda Red recombination system in $P$. aeruginosa [26]. However, this method can not produce scarless modification as the antibiotic cassette is still left on the genome DNA, quite difficult to perform multiple genes modification in one cell. And its homology regions were quite long, meaning several rounds of PCR amplification and more manipulation steps were needed. 
(A)

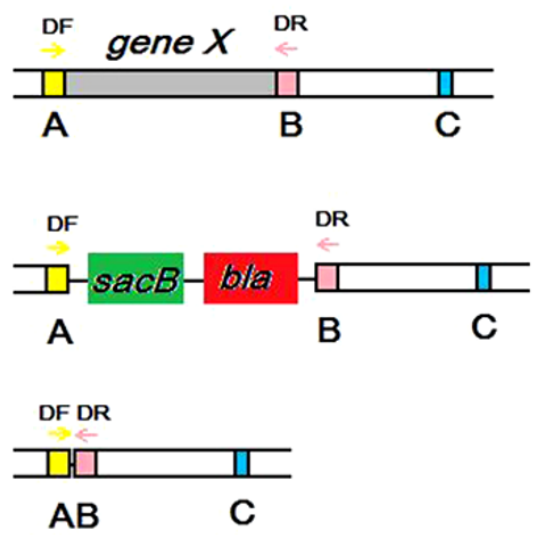

(B)

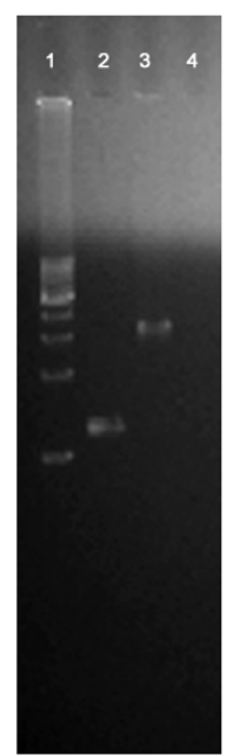

(C)

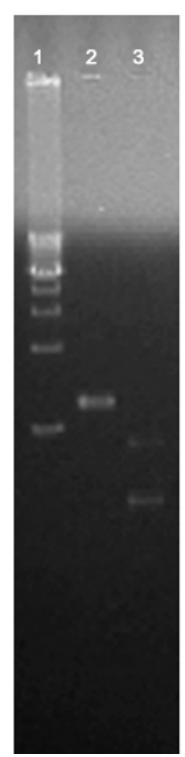

(D)

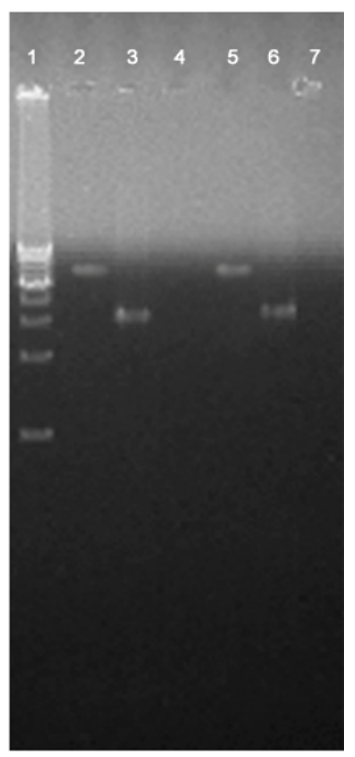

Figure 3 Plasmid pRKaraRed mediated scarless gene modification to PAO1 genome. (A). The scheme of the scarless gene modification. Primers DF and DR were used to verify the substitutions of target fragments. (B). PCR results of phzS deletion detected using primers phzS-DF and phzS-DR. Lanes: 1, DNA marker (Takara $1 \mathrm{~kb}$ marker, from $1.0 \mathrm{~kb}$ to $10.0 \mathrm{~kb}$ ); 2, the PCR product of phzS gene; 3 and 4, the PCR fragments corresponding to the recombination step 1 and step 2. (C). PCR results of the single-point mutation. Lanes: 1, DNA marker (as mentioned above); 2, the PCR product of phzS gene; 3, the Bam HI treated PCR fragment after the recombination of two steps. (D) PCR detection results of two operons deletions. Lanes: 1, DNA marker (as mentioned above); 2, the PCR product of phzA1G1 operon; 3 and 4, the PCR fragments corresponding to the recombination step 1 and step 2. The PCR amplifications were performed using primers phzA1G1-DF and phzA1G1-DR. Lanes: 5, the PCR product of phzA2G2 operon; 6 and 7, the PCR fragments corresponding to the recombination step 1 and step 2. The PCR amplifications were performed using primers phzA2G2-DF and phzA2G2-DR.

As previously reported, multi-copy Red plasmid pTP223 failed to promote gene replacement using the PCR-generated substrates with short homology extensions in E. coli, since the linear multimers of this plasmid generated through high dosage of lambda Gam protein drove the plasmid replication in rolling circle mode may be toxic to $E$. coli host or compete with the recombination substrates [27-30]. Based on these observations, we constructed plasmid pRKaraRed derived from RK2, low-copy and broad-host-range expression. As expected, plasmid pRKaraRed was able to promote efficient homologous recombination with short homology extension in E. coli, in $P$. aeruginosa PAO1, and also in Pseudomonas sp. M18 (data not shown). In E. coli, PCR cassettes flanked by only 35 bp homology region could induce the homologous recombination and efficient recombination happened when the PCR fragments flanked by 40 bp homology regions were used (data not shown). But in Pseudomonas PAO1 and M18, almost no transformant could be obtained using the PCR fragments with 35 bp or 40 bp homology extension, and at least $50 \mathrm{bp}$ homology regions were required for efficient recombination (30 80 transformants). This is consistent with previous results that the minimum length of homology extension required for efficient recombination may be different when the lambda Red system is used in different organisms, which may have relevance to the characteristics of the organisms, such as the difference in GC content and so on [22-25]. Although the efficiency of recombination in Pseudomonas was lower than that in E. coli, plasmid pRKaraRed was still suitable for the gene modification in Pseudomonas. Differences in the expression of Red proteins, DNA uptake, sequence contexts and the species-specific restriction may result in the variations of recombination efficiency [27].

The scarless modification strategy based on plasmid pRKaraRed was efficient and rapid. Single-point mutation, deletion of large operons and consecutive deletion of multiple genes could be achieved easily. One plasmid and PCR cassette flanked by 50 bp homology regions were enough to induce efficient recombination, meaning only one step PCR amplification was needed. And as the marker cassettes could be used repeatedly, only the homology regions should be changed to perform the modifications of different genes, which may alleviate the workload of primer design.

Furthermore, the expression of the lambda Red proteins were driven by the tightly regulated promoter $P_{B A D}$, of which the basal expression level was very low 
(A)

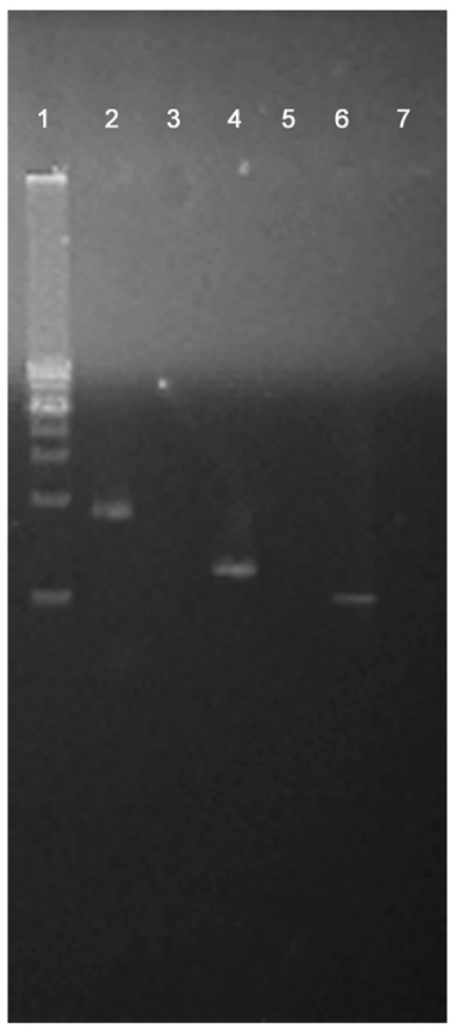

(B)
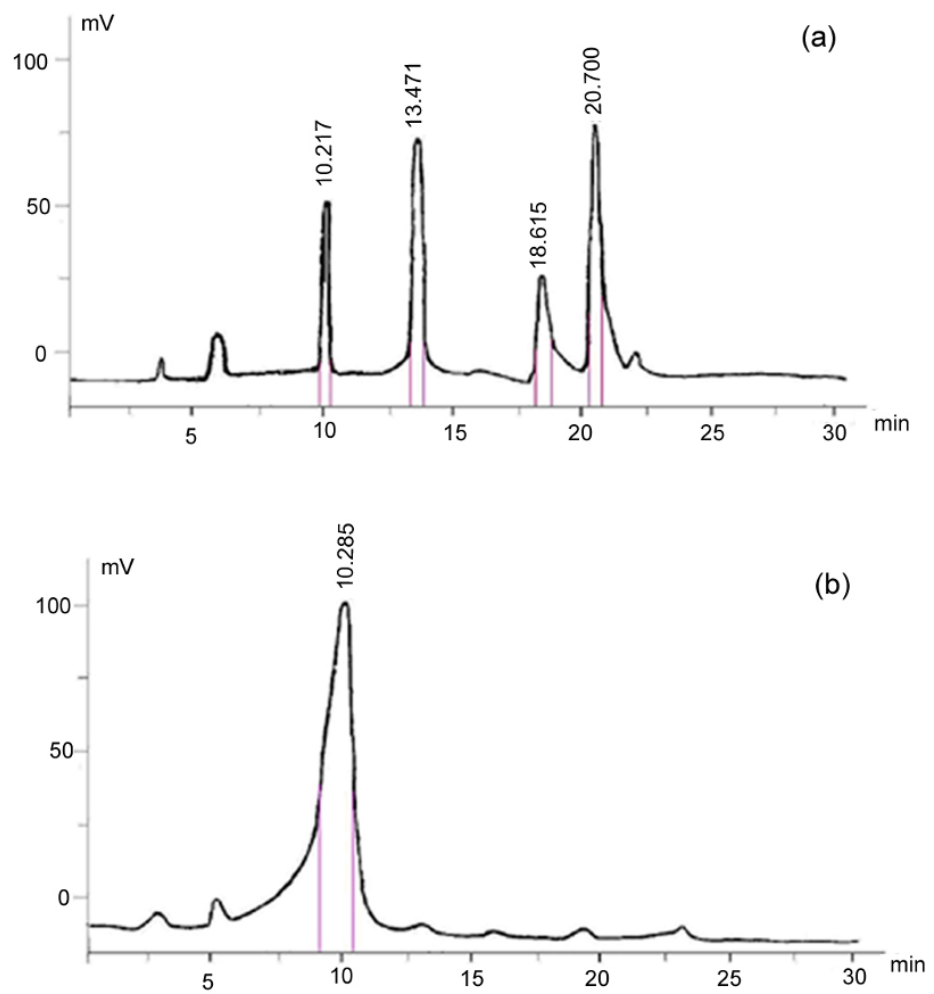

Figure 4 Sequential deletion of three genes $(p h z H, p h z M$ and $p h z S)$ and the HPLC analysis of phenazine derivatives in $P$. aeruginosa cultured media. (A). PCR detection results of strain PAO1 and strain PCA. Lane 1 was DNA marker (Takara 1 kb marker, from $1.0 \mathrm{~kb}$ to $10.0 \mathrm{~kb}$ ). Lanes 2, 4, 6 showed the PCR products with the PAO1 genome DNA as template, and lanes 3, 5, 7 showed those using the PCA genome DNA as template. Lanes 2 and 3, 4 and 5, 6 and 7 corresponded to PCR fragments obtained from the pair primers phzH-DF and phzH-DR, phzM-DF and phzM-DR, phzS-DF and phzS-DR, accordingly. (B). The HPLC results of the extracted phenazine derivatives from the cultured media of $P$. aeruginosa PAO1 (a) and P. aeruginosa PCA (b). The retention times were shown on the tops. MS was used to identify each fraction collected between the pink lines under the peak. Their chemical identities were PCA (9.17 min-10.43 min), PYO (13.42 min-13.93 min), PCN (18.34 min$18.97 \mathrm{~min}$ ), and 1-OH-Phz (20.42 min-20.93 min). Four phenazine derivates were detected in the cultured media of strain PAO1, while only PCA was detected in those of PCA strain.

in the absence of its inducer. This will minimize the unwanted recombination and increase the efficiency of homologous recombination. On the other hand, the sucrose counter-selection procedure could also increase the selection efficiency. Therefore, the high recombination efficiency of this strategy could ease the screening step, lessen work intensity and shorten the experimental time.

Phenazine derivates have many important biological effects [31,32]. Although the pathway of phenazine synthesis in $P$. aeruginosa has been studied [33], the function mechanisms and regulation networks of phenazine derivates are still poorly characterized. Therefore, many knockout mutants need to be constructed, not only single gene mutant, but also the multiple-gene mutants. Based on plasmid pRKaraRed mediated method, we successfully obtained a series of scarless deletion mutants of different genes involving in the phenazine synthesis and regulation pathways, such as lasI, $q s c R, g a c A, r s m A$ and $e t c$. Using this scarless approach, mutants with modifications of multiple genes could be generated easily for further study of the cumulative effects in different combination styles. Strain PCA with the deletion in three genes was an example. It could be further used to study the regulation styles and the special functions of this compound without any disturbance of other phenazine derivates.

In a word, the plasmid pRKaraRed mediated method could perform efficient and accurate homologous recombination in Pseudomonas and in E. coli. There is only one potential shortcoming of this system, that this plasmid can not be removed easily after all the necessary modifications are accomplished. Therefore, further improvements may be done, such as using the conditional 
replicons (e.g. temperature-sensitive replicon) to perfect this system.

\section{Conclusion}

This pRKaraRed-mediated technique could be used efficiently and rapidly to generate scarless and sequential gene modification mutants in $P$. aeruginosa with onestep PCR product flanked by short homology regions. Single-point mutation, large operon deletion mutants and sequential deletion mutants of multiple genes could be achieved easily. This method may give a new way to generate more genetically modified $P$. aeruginosa strains.

\section{Methods}

\section{Strains, plasmids, enzymes and chemicals}

All bacterial strains and plasmids used in this research were listed in Table 3. Luria-Bertani (LB) medium was used as a rich medium for both E. coli DH5 $\alpha$ and $P$. aeruginosa $\mathrm{PAO}$. Phenazine compounds fermentation medium was PB $\left(20 \mathrm{~g} / \mathrm{L}\right.$ Bacto Peptone, $1.4 \mathrm{~g} / \mathrm{L} \mathrm{MgCl}_{2}$ and $10 \mathrm{~g} / \mathrm{L} \mathrm{K}_{2} \mathrm{SO}_{4}$ ) [34]. The antibiotics carbenicillin (Carb, $500 \mu \mathrm{g} / \mathrm{ml}$ ) and/or tetracycline (Tet, $50 \mu \mathrm{g} / \mathrm{ml}$ ) were used if needed. $10 \%$ sucrose was used to identify the sucrose resistant or sensitive phenotype strain. Restriction enzymes, T4 DNA ligase, $L A-T a q^{\mathrm{Tm}}$ DNA polymerase, and Pyrobest ${ }^{\mathrm{Tm}}$ DNA polymerase were purchased from TaKaRa BIOTECH Co. (Dalian, China). All other reagents and chemicals were of analytical grade.

\section{PCR and standard DNA procedure}

PCR was performed with $L A-T a q$ DNA polymerase or Pyrobest DNA polymerase according to the manufacyturer's protocol. DNA sequences of the oligonucleotides were listed in Additional file 1, Table S1. Oligonucleotides synthesis and DNA sequencing were performed by Invitrogen Ltd. (Shanghai, China). Plasmid DNAs were isolated using the QIA prep Mini-spin kit (Qiagen, Shanghai, China) and $P$. aeruginosa genomic DNA was obtained using QIA amp DNA mini kit (Qiagen, Shanghai, China). DNA fragment were purified from agarose gels utilizing the QIA quick gel extraction kit (Qiagen, Shanghai,
China). Other general techniques for restriction enzyme manipulation, molecular cloning, and agarose gel electrophoresis were carried out with standard protocols.

\section{Construction of plasmid pRKaraRed}

The cassette containing araC gene and $P_{B A D}$ promoter was amplified from plasmid pBAD18 with primers araF and araR (Additional file 1, Table S1) [35]. The amplified DNA fragments were digested with restriction enzymes Kpn I and Xho I, and then they were cloned into plasmid pBluescript II KS (+), generating plasmid pKS-ara. Similar method was used to amplify the three genes (exo, bet and gam) of lambda-Red recombination system from lambda phage genomes with primers RedF and RedR, and inserted it into the Xho I-Bam HI site of plasmid pKS-ara, yielding plasmid pKS-araRed. The Kpn I-Bam $\mathrm{HI}$ fragment containing araC gene, $P_{B A D}$ promoter and three Red genes was further sub-cloned into the Kpn I-BamH I sites of RK2-derived cloning plasmid $\mathrm{pDN} 18$, generating the plasmid $\mathrm{pRKaraRed}$ able to express the lambda Red proteins (Fig. 1). DNA sequencing confirmed this construction.

\section{Electro-transformation of $P$. aeruginosa}

Single $P$. aeruginosa colony was inoculated in $3 \mathrm{ml} \mathrm{LB}$ medium and grown at $37^{\circ} \mathrm{C}$ overnight. $1 \mathrm{ml}$ overnight culture was added to $200 \mathrm{ml}$ fresh LB medium and grown at $37^{\circ} \mathrm{C}$, shaking to $\mathrm{OD}_{600}=0.4 \sim 0.5$. The bacteria were then rendered electro-competent by four times washings of icecold $10 \%$ glycerol and were re-suspended in $200 \mu \mathrm{l}$ icecold $10 \%$ glycerol. To generate the electro-competent cells of PAO1/pRKaraRed, L-arabinose of certain concentration should be added into the medium and cultured for several hours before the $10 \%$ glycerol washing step.

Electroporation was carried out using $50 \mu \mathrm{l}$ of bacterial suspension (about $1 \times 10^{9}$ cells) and no more than $10 \mu \mathrm{l}$ of DNA (at least $200 \mathrm{ng} / \mu \mathrm{l}$ ) in a $0.2 \mathrm{~cm}$ ice-cold electroportation cuvette, transformed on a Bio-Rad GenePulser II at $200 \Omega, 25 \mu \mathrm{F}$ and $2.5 \mathrm{kV}$. Uninduced cells and induced cells without plasmid or without DNA fragments were set as negative controls for each transformation. The

Table 3 Bacterial strains and plasmids

\begin{tabular}{|c|c|c|}
\hline Strains and Plasmids & Genotype or Description & Source \\
\hline E. coli DH5 $\alpha$ & 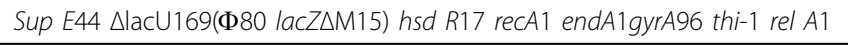 & Gibco-BRL \\
\hline P. aeruginosa PAO1 & Wild type prototroph & Stephen Lory's Lab \\
\hline P. aeruginosa PCA & PAO1 $\Delta p h z H \Delta p h z S \Delta p h z M$ & This work \\
\hline Plasmid pDN18 & RK2-derived cloning vector, Tet $^{R}$ & Stephen Lory's Lab, [18] \\
\hline pBluescript II KS (+) & Universal cloning vector, $\mathrm{Amp}^{\mathrm{R}}$ & Stratagene \\
\hline pEX18Ap & Gene replacement vector, orit ${ }^{+} s a c B^{+}, A m p^{R}$ & Stephen Lory's Lab, [16] \\
\hline pBAD18 & Vector containing araC gene and $P_{B A D}$ promoter, $\mathrm{Amp}^{\mathrm{R}}$ & [35] \\
\hline pRKaraRed & Broad-host-range, lambda Red proteins expression vector, Tet $^{R}$ & This work \\
\hline
\end{tabular}


electroporated cells were diluted in $1 \mathrm{ml} \mathrm{LB}$ and incubated at $37^{\circ} \mathrm{C}$ for three hours. The transformants were then selected on the antibiotic-imbued plates.

\section{Scarless gene modification in $P$. aeruginosa}

Scarless gene modification strategy was described in Fig. 2. First the sacB-bla cassettes were amplified from plasmid pEX18Ap with the primers F1 and R1 [16]. The numbers of primers corresponded to the steps of PCR amplification. The electro-transformation of the $s a c B$-bla cassette into the PAO1/pRKaraRed competent cells was performed as described above. Transformants were screened on LB plates supplemented with $500 \mu \mathrm{g} / \mathrm{ml}$ carbenicillin and 50 $\mu \mathrm{g} / \mathrm{ml}$ tetracyclin. The colonies with $\mathrm{Carb}^{\mathrm{R}} \mathrm{Tet}^{\mathrm{R}}$ phenotypes confirmed by PCR detection and DNA sequencing were regarded as positive clones. Next, the sacB-bla removal cassettes were amplified from the genomic DNA of the first-step strain with the primers F2 and R2. Then this fragment was electro-transformed into the competent cells of the first-step to perform the second recombination. Electro-transformed cells were spread on LB plates supplemented with $10 \%$ sucrose and $50 \mu \mathrm{g} / \mathrm{ml}$ tetracycline. The transformants were further selected parallel on the LB plates with $10 \%$ sucrose and $50 \mu \mathrm{g} / \mathrm{ml}$ tetracycline, and the LB plates with $500 \mu \mathrm{g} / \mathrm{ml}$ carbenicillin and $50 \mu \mathrm{g} / \mathrm{ml}$ tetracycline. The colonies with $\mathrm{Suc}^{\mathrm{R}} \mathrm{Carb}^{\mathrm{S}}$ phenotypes confirmed by PCR detection and DNA sequencing were regarded as positive recombinants.

Twelve genes, two large operons and one nucleotide site were selected as target and their primers for PCR amplification were listed in Additional file 1, Table S1.

\section{System efficiency analysis}

The influences of $\mathrm{L}$-arabinose concentration, induction time and the length of homology region on the efficiency of homologous recombination were analyzed. phzS gene was selected as target. First, the PAO1/pRKaraRed cultures were induced with $\mathrm{L}$-arabinose of different concentrations (ranging from $0.05 \%$ to $1.0 \%$ ) for three hours. Then the PAO1/pRKaraRed cultures were induced with $\mathrm{L}$-arabinose of suitable concentration for different time (from $1 \mathrm{~h}$ to $12 \mathrm{~h}$ ). Finally, the PCR products with homology regions of different lengths (50 bp, $60 \mathrm{bp}, 100 \mathrm{bp}$ ) were used to perform homologous recombination. Control experiments and screen procedures were set same as described above. The efficiencies of recombination were calculated by dividing the number of positive colonies with the number of growing colonies.

\section{Construction of three-gene deleted strain PCA and HPLC analysis of phenazine derivatives}

Sequential gene modifications of multiple target genes were achieved by several rounds of recombination steps. The recombination efficiency was also detected using phenotype screen, PCR detection and DNA sequencing. The strain with three-gene deletions (PAO1, $\Delta p h z H \Delta p h z M \Delta p h z S)$ was named as PCA.

HPLC analysis of phenazine derivatives were performed as previously described [33]. PAO1 and PCA strains were cultured in $\mathrm{PB}$ medium at $28^{\circ} \mathrm{C}$ for $72 \mathrm{~h}$ and then centrifugation was performed to remove the cells. The recovered medium was acidified to $\mathrm{pH} 4.0$ with $\mathrm{HCl}$ and filtered through $0.22 \mu \mathrm{m}$ membrane. The filtrates were extracted with chloroform. The organic phase was dried with nitrogen and dissolved in acetonitrile. $10 \mu \mathrm{l}$ samples were loaded onto a Unimicro Kromasil C18 column $(5 \mu \mathrm{m} ; 4.6$ by $250 \mathrm{~mm}$, ScienHome Co., USA) for reverse-phase HPLC analysis in a Waters HPLC Integrity system consisting of a Waters 510 separation module and a $490 \mathrm{E}$ programmable multiwavelength detector. The column was washed at a flow rate $500 \mu \mathrm{l} / \mathrm{min}$ with $8 \%$ acetonitrile in $25 \mathrm{mM}$ ammonium acetate for $2 \mathrm{~min}$ and a linear gradient acetonitrile from $8 \%$ to $80 \%$ in $25 \mathrm{mM}$ ammonium acetate for $25 \mathrm{~min}$. The HPLC was monitored simultaneously at $257 \mathrm{~nm}$. The peak fractions were collected separately and identified by mass spectrometry with HP1100 HPLCMSD (API-ES/APCI) (Hewlett-Packard Co., USA).

\section{Additional material}

Additional file 1: Table S1 - Oligonucleotides used for PCR amplifications.

\section{Acknowledgements}

We are grateful to Dr. Stephen Lory (Harvard Medical School) for providing bacterial strains and plasmids to initiate this work.

This work was supported by grant from the National Natural Science Foundation of China [grant number 30900010, 30870512]; grant from the Science Foundation for the Excellent Youth Scholars of Ministry of Education of China [grant number No. 20090073120066]; the Major State Basic Research Development Program of China (973 Program) [grant number 2009CB118906, 2007CB914504].

\section{Authors' contributions}

$\mathrm{RL}$ conceived of the study, carried out all the molecular genetic studies and HPLC analysis, participated in the sequence alignment and drafted the manuscript. $J$ conceived of the study, participated in its design and coordination.

All authors have read and approved the final manuscript.

Received: 12 April 2010 Accepted: 3 August 2010

Published: 3 August 2010

\section{References}

1. Pósfai G, Plunkett GIII, Feher T, Frisch D, Keil GM, Umenhoffer K, Kolisnychenko V, Stahl B, Sharma SS, de Arruda M, Burland V, Harcum SW, Blattner FR: Emergent properties of reduced genome Escherichia coli. Science 2006, 312:1044-1046.

2. Suzuki N, Okayama S, Nonaka H, Tsuge Y, Inui M, Yukawa H: Large-scale engineering of the Corynebacterium glutamicum genome. Appl Environ Microbiol 2005, 71:3369-3372. 
3. Westers H, Dorenbos R, van Dijl JM, Kabel J, Flanagan T, Devine KM, Jude F, Seror SJ, Beekman AC, Darmon E, Eschevins C, de Jong A, Bron S, Kuipers OP, Albertini AM, Antelmann H, Hecker M, Zamboni N, Sauer U, Bruand C, Ehrlich DS, Alonso JC, Salas M, Quax WJ: Genome engineering reveals large dispensable regions in Bacillus subtilis. Mol Biol Evol 2003, 20:2076-2090.

4. Muyrers JP, Zhang Y, Stewart AF: Techniques: Recombinogenic engineering-new options for cloning and manipulating DNA. Trends Biochem Sci 2001, 26:325-331.

5. Ellis HM, Yu D, DiTizio T, Court DL: High efficiency mutagenesis, repair, and engineering of chromosomal DNA using single-stranded oligonucleotides. Proc Natl Acad Sci USA 2001, 98:6742-6746.

6. Murphy KC: Use of bacteriophage lambda recombination functions to promote gene replacement in Escherichia coli. J Bacteriol 1998, 180:2063-2071

7. Yu D, Ellis HM, Lee EC, Jenkins NA, Copeland NG, Court DL: An efficient recombination system for chromosome engineering in Escherichia coli. Proc Natl Acad Sci USA 2000, 97:5978-5983.

8. Yu D, Sawitzke JA, Ellis H, Court DL: Recombineering with overlapping single-stranded DNA oligonucleotides: testing a recombination intermediate. Proc Natl Acad Sci USA 2003, 100:7207-7212.

9. Schweizer HP: Applications of the Saccharomyces cerevisiae Flp-FRT system in bacterial genetics. J Mol Microbiol Biotechnol 2003, 5:67-77.

10. Copeland NG, Jenkins NA, Court DL: Recombineering: a powerful new tool for mouse functional genomics. Nat Rev Genet 2001, 2:769-779.

11. Stover CK, Pham XQ, Erwin AL, Mizoguchi SD, Warrener P, Hickey MJ, Brinkman FS, Hufnagle WO, Kowalik DJ, Lagrou M, Garber RL, Goltry L, Tolentino E, Westbrock-Wadman S, Yuan Y, Brody LL, Coulter SN, Folger KR, Kas A, Larbig K, Lim R, Smith K, Spencer D, Wong GK, Wu Z, Paulsen IT, Reizer J, Saier MH, Hancock RE, Lory S, Olson MV: Complete genome sequence of Pseudomonas aeruginosa PAO1, an opportunistic pathogen. Nature 2000, 406:959-964

12. Schweizer HP, de Lorenzo V: Molecular tools for genetic analysis of pseudomonad sp. The Pseudomonads - Genomics, life style and molecular architecture New York, Kluwer Academic/PlenumRamos JL 2004, I:317-350.

13. Suh SJ, Silo-Suh LA, Ohman DE: Development of tools for the genetic manipulation of Pseudomonas aeruginosa. J Microbiol Method 2004, 58:203-212.

14. Goodman AL, Lory S: Analysis of regulatory networks in Pseudomonas aeruginosa by genome wide transcriptional profiling. Curr Opin Microbiol 2004, 7:39-44.

15. Jacobs MA, Alwood A, Thaipisuttikul I, Spencer D, Haugen E, Ernst S, Will O, Kaul R, Raymond C, Levy R, Chun-Rong L, Guenthner D, Bovee D, Olson MV, Manoil C: Comprehensive transposon mutant library of Pseudomonas aeruginosa. Proc Natl Acad Sci USA 2003, 100:14339-14344.

16. Hoang TT, Karkhoff-Schweizer RR, Kutchma AJ, Schweizer HP: A broad-hostrange Flp-FRT recombination system for site-specific excision of chromosomally-located DNA sequences: application for isolation of unmarked Pseudomonas aeruginosa mutants. Gene 1998, 212:77-86.

17. Quénée $L$, Lamotte $D$, Polack $B$ : Combined sacB-based negative selection and cre-lox antibiotic marker recycling for efficient gene deletion in Pseudomonas aeruginosa. Biotechnique 2005, 38:63-67.

18. Nunn D, Bergman S, Lory S: Products of three accessory genes, pilB, pilC, and pilD, are required for biogenesis of Pseudomonas aeruginosa pili. J Bacteriol 1990, 172:2911-2919.

19. Schmidhauser TJ, Helinski DR: Regions of broad-host-range plasmid RK2 involved in replication and stable maintenance in nine species of gramnegative bacteria. J Bacteriol 1985, 164:446-455.

20. Guiney DG, Yakobson E: Location and nucleotide sequence of the transfer origin of the broad host range plasmid RK2. Proc Natl Acad Sci USA 1983, 80:3595-3598.

21. Datsenko KA, Wanner BL: One-step inactivation of chromosomal genes in Escherichia coli K-12 using PCR products. Proc Natl Acad Sci USA 2000, 97:6640-6645.

22. Lesic B, Bach S, Ghigo JM, Dobrindt U, Hacker J, Carniel E: Excision of the high-pathogenicity island of Yersinia pseudotuberculosis requires the combined actions of its cognate integrase and Hef, a new recombination directionality factor. Mol Microbiol 2004, 52:1337-1348.

23. Husseiny MI, Hensel M: Rapid method for the construction of Salmonella enterica Serovar Typhimurium vaccine carrier strains. Infect Immun 2005, 73:1598-1605.
24. Beloin C, Deighan P, Doyle M, Dorman CJ: Shigella flexneri 2a strain 2457T expresses three members of the H-NS-like protein family: characterization of the Sfh protein. Mol Genet Genomics 2003, 270:66-77.

25. Rossi MS, Paquelin A, Ghigo JM, Wandersman C: Haemophoremediated signal transduction across the bacterial cell envelope in Serratia marcescens: the inducer and the transported substrate are different molecules. Mol Microbiol 2003, 48:1467-1480.

26. Lesic B, Rahme LG: Use of the lambda Red recombinase system to rapidly generate mutants in Pseudomonas aeruginosa. BMC Mol Biol 2008, 9:20.

27. Murphy KC, Campellone KG: Campellone. Lambda Red-mediated recombinogenic engineering of enterohemorrhagic and enteropathogenic E. coli. BMC Mol Biol 2003, 4:11.

28. Friedman SA, Hays JB: Selective inhibition of Escherichia coli recBC activities by plasmid-encoded GamS function of phage lambda. Gene 1986, 43:255-263.

29. Poteete AR, Fenton AC, Murphy KC: Modulation of Escherichia coli RecBCD activity by the bacteriophage lambda Gam and P22 Abc functions. J Bacteriol 1988, 170:2012-2021.

30. Silberstein Z, Maor S, Berger I, Cohen A: Lambda Red-mediated synthesis of plasmidlinear multimers in Escherichia coli K12. Mol Gen Genet 1990, 223:496-507.

31. Gibson J, Sood A, Hogan DA: Pseudomonas aeruginosa-Candida albicans interactions: localization and fungal toxicity of a phenazine derivative. Appl Environ Microbiol 2009, 75:504-513.

32. Denning GM, lyer SS, Reszka KJ, O'Malley Y, Rasmussen GT, Britigan BE: Phenazine-1-carboxylic acid, a secondary metabolite of Pseudomonas aeruginosa, alters expression of immunomodulatory proteins by human airway epithelial cells. Am J Physiol Lung Cell Mol Physiol 2003, 285 L584-592.

33. Mavrodi DV, Bonsall RF, Delaney SM, Soule MJ, Phillips G, Thomashow LS: Functional analysis of genes for biosynthesis of pyocyanin and phenazine-1-carboxamide from Pseudomonas aeruginosa PAO1. J Bacteriol 2001, 183:6454-6465.

34. Essar DW, Eberly L, Hadero A, Crawford IP: Identification and characterization of genes for a second anthranilate synthase in Pseudomonas aeruginosa: interchangeability of the two anthranilate synthases and evolutionary implications. J Bacteriol 1990, 172:884-900.

35. Guzman LM, Belin D, Carson MJ, Beckwith J: Tight regulation, modulation, and high-level expression by vectors containing the arabinose $\mathrm{P}_{\mathrm{BAD}}$ promoter. J. Bacteriol 1995, 177:4121-4130

doi:10.1186/1471-2180-10-209

Cite this article as: Liang and Liu: Scarless and sequential gene modification in Pseudomonas using PCR product flanked by short homology regions. BMC Microbiology 2010 10:209.

\section{Submit your next manuscript to BioMed Central and take full advantage of:}

- Convenient online submission

- Thorough peer review

- No space constraints or color figure charges

- Immediate publication on acceptance

- Inclusion in PubMed, CAS, Scopus and Google Scholar

- Research which is freely available for redistribution 